\title{
Introducing the transformative service mediator: value creation with vulnerable consumers
}

\author{
Raechel fohns \\ Canberra Business School, University of Canberra, Canberra, Australia, and \\ Fanet Davey \\ School of Marketing and International Business, Victoria University of Wellington, Wellington, New Zealand
}

\begin{abstract}
Purpose - The purpose of this study is to identify the role of mediators in supporting value co-creation for vulnerable consumers in a service context. The authors propose that in transformative services, the roles of actor mediators facilitate control and empowerment for the vulnerable consumer - labelling these transformative service mediators (TSMs).

Design/methodology/approach - The authors develop a theoretical framework for the activities of mediators in value co-creation considering the interrelationships of vulnerability, structure and agency. The authors then use Prahalad and Ramaswamy's DART (Dialogue, Access, Risk Assessment and Transparency) model as the integrating framework to describe the TSM roles in the context of the foster care service ecosystem.

Findings - The authors introduce a future research agenda regarding TSM roles in transformational service experiences and value co-creation with vulnerable consumers. Service researchers and providers are encouraged to explore effective training and motivation of TSMs.

Research limitations/implications - Understanding value co-creation for vulnerable consumers is an emerging area in service research. The TSM concept introduces a new approach to explore how value co-creation and transformative outcomes can be enhanced in service contexts where consumers experience vulnerability.

Practical implications - This paper presents an agenda for future research. The outcomes of future research based on TSM roles may help guide service providers in identifying opportunities for enhancing well-being and reducing vulnerability in service delivery.

Originality/value - This paper suggests that exploring the role of TSMs in the service process offers new insights into reducing vulnerability in service relationships.
\end{abstract}

Keywords Customer value, Agency, Co-creation, Intermediaries, Well-being, Transformative, Value co-creation, Customer participation, Vulnerable consumers, Transformational service, Apomediaries

Paper type Conceptual paper

\section{Introduction}

\section{The context}

According to the logics of service, interaction is the basis of value creation and value fulfilment. Inherent in this understanding of value creation is individual actor agency in the service ecosystem (Grönroos, 2008; Lusch and Vargo, 2014). The customer is deemed to be capable, effortful, willing and enabled to engage the resources from a network of actors within the service provider ecosystem and beyond (other service providers, other customers, peers, family and friends) to create value. Service research literature predominantly suggests that value co-creation should occur as it confers mutually beneficial outcomes for the firm, the customer and network partners (Payne et al., 2008; Vargo and Lusch, 2006; Vargo and Lusch, 2016). The associated expectation is that actors can integrate resources and exchange service in the processes of value cocreation (Akaka and Chandler, 2011; Prahalad and

The current issue and full text archive of this journal is available on Emerald Insight at: www.emeraldinsight.com/0887-6045.htm

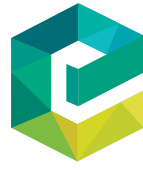

Journal of Services Marketing

33/1 (2019) 5-15

(C) Emerald Publishing Limited [ISSN 0887-6045]

[DOI 10.1108/JSM-10-2018-0282]
Ramaswamy, 2004). However, even when value co-creation processes are enabled by institutional norms and structures or when they occur across different levels of service networks (dyad, family, peers groups, inter-firm, etc.), can all consumers co-create value?

Some consumers have diminished resources and skills to apply to their value-generating processes (Dickson et al., 2016; Grönroos, 2008), and are consequently involved in the value co-creation processes in different ways (McColl-Kennedy et al., 2012). For these service consumers, other actors in the service ecosystem necessarily take on a pivotal role in value creation. While scholars have called for a better understanding of how service providers can enhance consumer well-being (Anderson et al., 2013; Ostrom et al., 2015), few studies have investigated actor mediator roles in transformative service outcomes. Therefore, to achieve a more complete understanding of value co-creation within service networks and systems, we explore actor mediator roles in transformative services in the context of consumer vulnerability. By doing so, we also respond to calls for a shift in research from an emphasis on the service provider and supplier in managing value co-creation to understanding "intermediaries in co-creation" (Payne et al., 2008, p. 94).

Received 7 October 2018

Revised 6 November 2018

Accepted 28 November 2018 
This conceptual paper addresses these gaps in our understanding by exploring mediator roles in transformative service processes, considering how they enable or constrain value creation outcomes for vulnerable consumers. We define vulnerable consumers as those whose individual characteristics or individual states interact with the environment to create a state of powerlessness in consumption situations such that their service exchange goals are not realised (Baker et al., 2005; Rosenbaum et al., 2017), for example, children, immigrants or people with a disability. In addition, dependency can also be considered vulnerability (Dodds, 2014). To illustrate the role of value creation in the service ecosystem with vulnerable consumers, we focus on one context of vulnerability, namely, dependency - specifically, children in foster care. As service consumers, children in foster care typically experience a degree of powerlessness, and along with their dependency on others in the service experience, thus fit our definition of vulnerability.

\section{The research question and purpose}

In conditions of vulnerability, a consumer may not have the resources, capabilities or authority to exercise resourceintegrating roles. Moreover, service structures and processes are known to hinder vulnerable consumers' resourceintegrating behaviours, sometimes through discriminatory practices, often triggering retaliatory behaviour towards the service provider (Crockett et al., 2013; Johns et al., 2017). Consequently, service interactions and value-creating processes may be purposefully mediated by others. These people, who may act for either or both the service provider and the consumer, undertake a variety of activities that constrain or enhance service value. To cover the roles undertaken by these mediators, we introduce transformative service mediators (TSM). This term is used to describe a range of activities, which, here, we categorise as either an intermediary or apomediary (Eysenbach, 2008).

We adapt Latour (2005) and Storbacka et al. (2016) notions on intermediaries and mediators. Storbacka et al. (2016) maintain that intermediaries do not transform inputs but merely facilitate processes; only mediators transform inputs through their engagement. Our theoretical framework describes intermediaries as facilitating the resources of another actor (e.g. of the service provider), which may involve rudimentary participation in the service interaction, but which may not necessarily lead to transformative outcomes. Contrastingly, the transformative apomediary, through participation in the service interaction and experience, augments the existing resources within the service system and through resource integrating activities creates value that leads to transformative service outcomes, namely, reducing suffering and enhancing well-being. However, we diverge from Storbacka et al.'s (2016) position, proposing that intermediaries and transformative apomediaries exist on a continuum of mediation.

By differentiating service mediating roles, we add a nuanced understanding to value co-creation processes in transformative service provision for vulnerable consumers. We purposefully distinguish between intermediaries and apomediaries in the theoretical framework we develop as the foundation for the research agenda.
In our theoretical framework, TSMs are situated not only between the service provider and the vulnerable consumer but also alongside vulnerable consumers in transformative service provision. Importantly, these actor mediators act through and within the layers of systems, processes, people and networks. To understand how TSMs function in value co-creation, we use the Dialogue, Access, Risk Assessment and Transparency (DART) model developed by Prahalad and Ramaswamy (2004). Our paper, thus, provides support for the emerging emphasis in transformative services on the service system and network processes, moving away from a dyadic focal customersupplier relationship. Our research question is:

RQ1. How do TSMs contribute to value co-creation for vulnerable consumers?

The purpose of this paper, therefore, is to propose a research agenda that can develop the service marketing literature through a greater understanding of how TSMs enhance consumer well-being in the specific service context of vulnerable consumers. This research agenda seeks to provide a further understanding of how the TSM provides a transformational service experience for or with vulnerable consumers; assist vulnerable consumers to co-create value; and empower vulnerable consumers. Greater understanding of ways to effectively recruit, train and motivate TSMs is also necessary, and recommended through the research agenda.

\section{The structure of the paper}

Towards answering this research question, the paper commences with a brief overview of transformative service research (TSR), followed by consumer vulnerability. Next, we describe briefly the concepts of secondary customers (Leino, 2017) and individual agency. Using the DART framework of value co-creation (Prahalad and Ramaswamy, 2004), the subsequent section presents our theoretical framework of TSM roles and activities. As an illustration of TSM roles in value creation for vulnerable consumers, the case scenario of foster care for children is described. The next section proposes a research agenda for mediation in service co-creation for vulnerable consumers and we introduce research questions according to vulnerability definitions and the organising framework of DART. The paper concludes with a discussion of the theoretical and practical implications from this discussion.

\section{Transformative service research}

Service literature has traditionally focussed on service processes between an organisation and a customer electing to have service, however, with a burgeoning interest in TSR, a body of literature now explores service delivery as a way of improving consumer and societal well-being (Rosenbaum et al., 2011). Despite this increased emphasis in the academic literature, further research is required (Hepi et al., 2017) to operationalise 1TSR. While traditional service provision emphasises profitability and satisfaction outcomes, TSR emphasises consumer well-being, and service researchers and practitioners have been called upon to engage in TSR and activities (Rosenbaum et al., 2011) to have a deeper understanding of well-being through service. 
TSR focusses on co-creation of well-being (Rosenbaum et al., 2011) and is defined as "service research that centres on creating uplifting changes and improvements in the well-being of individuals (consumers and employees), families, social networks, communities, cities, nations, collectives and ecosystems" (Anderson et al., 2011, p. 3). More recently, researchers are extending the definition of TSR to include the reduction of suffering (for example, via reducing discriminatory practices or unfairness in service design) as a precursor to enhanced well-being (Nasr and Fisk, 2018). To date, limited research has linked value co-creation with TSR (Pera and Viglia, 2015); however, some scholars are now emphasising this intersection to extend our understanding of TSR (Hardyman et al., 2015). This conceptual paper and our research agenda in the context of transformative services for vulnerable consumers make a contribution in this space.

\section{Transformative service context - vulnerable consumers within a transformative service ecosystem}

With the increasing focus on TSR, it is important to further understand how, when and for whom services are transformational. Our paper extends services marketing thinking around services for those consumers, who are either disadvantaged during (and because of) the service process or are vulnerable in the service process because of their internal or external (to the service process) characteristics. Because of the assumption in much of the service literature that service encounters are directly undertaken between the service recipient and service provider (Klaus and Maklan, 2007; Prahalad and Ramaswamy, 2004), there is a need to explore how the system of resource integrating actors and institutional arrangements operate in contexts of consumer vulnerability, where direct interaction may not always be possible.

Consumer vulnerability is increasingly explored in the academic literature, yet, it is often misunderstood or misused as a concept (Baker et al., 2005). Although the definition of vulnerability is contested (Andreasen and Manning, 1990; Halstead et al., 2007; Mansfield and Pinto, 2008; Spotswood and Nairn, 2016), this paper uses Baker's (2005) definition of consumer vulnerability as:

[...] a state of powerlessness that [...] occurs when control is not in an individual's hands, creating a dependence on external factors (e.g. marketers) to create fairness in the marketplace [...] [and] where consumption goals may be hindered [...] (p. 134).

Vulnerable consumers can include those with disabilities, the elderly, those from the LGBTIQA community, immigrants, those with mental health concerns, obese people, those living in remote communities or children (Fisk et al., 2018; Rosenbaum et al., 2017). Consumer vulnerability is generally considered a latent state but vulnerability can be triggered during the service process, for example, when a consumer is not treated fairly in service delivery or when value inherent in the service activity is not realised (Rosenbaum et al., 2017). Consumers have differing responses to vulnerability and on the basis of their coping strategies, resources and situational factors (Baker et al., 2005), will manage situations in which they are deemed to be vulnerable in varied ways.
Based on a literature review, Table I provides a brief overview of factors that can result in consumer vulnerability. All consumers can experience vulnerability at any point in time because vulnerability may be temporary (e.g. grief or a feeling of unease) compared with permanent vulnerability (e.g. a lifelong disability). A temporary state can also include a temporary disability (Dickson et al., 2016). For example, a high-risk pregnancy could make a consumer more vulnerable temporarily, but this would change once the pregnancy is complete (Dickson et al., 2016). While vulnerability may be triggered by a particular event or characteristic, Baker and Mason (2012) also propose that vulnerability should be understood in terms of the ongoing tensions that occur in experiencing and/or attempts to reduce the vulnerability.

Vulnerability poses several problems for transformative services and value co-creation. In particular, vulnerable consumers may "fail to understand their own preferences and/ or lack the knowledge, skills or freedom (i.e. personal prerogatives and marketplace options) to act on them" (Ringold, 2005, p. 202). Thus, vulnerable consumers may not be able to navigate the service system, they may lack the information to set goals, and they may lack the freedom to achieve goals. These consequences of vulnerability echo, in the reverse, the description of requisite resource integrating activities for value co-creation (Vargo and Lusch, 2004, 2006) and thus necessitate other actors to mediate service processes.

An understanding of these mediating roles is discussed in this paper. Vulnerability and dependence in relation to value cocreating processes and experiences expose fundamental issues of individual agency and the closely related notion of the extended consumer entity or secondary consumers. These two concepts are discussed next.

\section{Individual agency}

According to SD logic, value co-creation occurs through resource integration where the consumer realises benefit through interacting with others in their service ecosystem (Vargo and Lusch, 2006). In this logic, it is assumed that the consumer is an active and capable resource integrator within a set of institutional arrangements and processes that include norms and rules guiding the behaviour of other service ecosystem actors and social agents (Vargo and Lusch, 2016). This enactment of resources, providing the capability for value co-creation is, however, premised on actors' agency (Edvardsson et al., 2014) embedded within the set of social practices and contexts that make up the service ecosystem (Street, 2001; Vargo and Lusch, 2016).

Human agency, defined as the presence or absence of choice and how much control a consumer has in those choices (Archer, 2000), includes aspects of efficacy, competency and freedom (Anderson et al., 2016). Agency, therefore, enables actors to act upon resources to create value and "depends profoundly on their [individual person's] positions in collective organizations" (Sewell, 1992, p. 21). Within TSR and SDL logics, resource integrating actors are typically described as those who "possess appropriate resources which they are allowed and able to share, co-creating value using collaborative and integrative processes [...] impact[ing] the ability of actors to exercise agency" (Kleinaltenkamp et al., 2012, p. 201). We propose that TSMs are positioned to act as these resource 
Table I Key factors causing consumer vulnerability

\begin{tabular}{|c|c|}
\hline Factors causing vulnerability & Author/s \\
\hline $\begin{array}{l}\text { Individual characteristics } \\
\text { e.g. age, gender and disability/ability }\end{array}$ & Baker et al. (2005), Rosenbaum et al. (2017) \\
\hline $\begin{array}{l}\text { Individual states, can be permanent or temporary } \\
\text { e.g. grief, transition and motivation }\end{array}$ & Baker et al. (2005), Commuri and Ekici (2008), McAlexander et al. (1993) \\
\hline $\begin{array}{l}\text { External conditions, can be caused by internal issues or } \\
\text { societal/external issues } \\
\text { e.g. homelessness, disaster recovery and migration } \\
\text { (particularly fleeing persecution) } \\
\text { May include spatial vulnerability e.g. public space, } \\
\text { social space and digital space. }\end{array}$ & Baker et al. (2005), Hogg et al. (2007), Nasr and Fisk (2018), Saatcioglu and Corus (2016) \\
\hline $\begin{array}{l}\text { Inequity and service exclusion } \\
\text { e.g. lack of fairness in service provision }\end{array}$ & Baker et al. (2005), Dickson et al. (2016), Fisk et al. (2018) \\
\hline $\begin{array}{l}\text { Dependence } \\
\text { e.g. lack of power, requires support from others, such } \\
\text { as a child unable to act for themselves. Could be } \\
\text { influenced by all other factors causing vulnerability }\end{array}$ & Dodds (2014) \\
\hline $\begin{array}{l}\text { Macro forces of environments, social structures, } \\
\text { regulations and technology availability } \\
\text { e.g. media and including advertising }\end{array}$ & Baker and Mason (2012), McKeage et al. (2018) \\
\hline
\end{tabular}

integrating actors where the vulnerability exists in a service relationship.

While structures may constrain consumer agency in service systems (Giesler and Veresiu, 2014), the actors' own knowledge, skills, as well as their intentions and motivation may also hinder their capability for the agency (Edvardsson et al., 2014). Importantly, in the case of vulnerable consumers who already face resource scarcities (as discussed above), asymmetries of expertise, information and power combine to constrain their consumer agency. At the same time, an individual's vulnerability means that much of the agentic resources in a service relationship are transferred to actors other than the service beneficiary, who transform inputs into valuein-use to facilitate movement for the consumer towards empowerment and "away from vulnerability" (Baker et al., 2005 , p. 136). The boundaries, then, of the agency of vulnerable consumers are blurred with those of mediators, who have the resources to influence action (Sewell, 1992) and realise the potential of value co-creating resources. As "value is an interaction experience" (FitzPatrick et al., 2015, p. 465), service transformation in vulnerability contexts will occur within nested layers of interaction between the service provider and the consumer. The mediation of human agency in such contexts highlights the complexity of transformative value creation for vulnerable consumers.

\section{Transformative service with secondary consumers}

Recently in the context of vulnerability and healthcare, the mediator role has been classified as a "secondary consumer" (Leino, 2017). These secondary consumers are defined as "individuals or groups from outside the process boundaries who also receive process output, but who are not the reason for the processes' existence" (Westcott, 2005, p. 450). Family members and close contacts often plays a major role in service provision for healthcare consumers. Thus, several individuals can be aligned to a "focal" consumer, where service provision impacts all members of the "collective" (Anderson et al., 2013; Sweeney et al., 2015), for example, informal caregivers, charitable organisations (hospice visits). Despite this, there lacks sufficient attention on understanding the needs of family members or other supporters in terms of care services (Hudson et al., 2010).

Secondary consumers are clearly actors in the service ecosystem. The idea of an extended consumer entity moves the consideration of value away from a single actor-firm interaction. While this is beneficial, the secondary function connotes a service recipient or beneficiary, in our view giving insufficient attention to the context of transformative service processes and extended value-creating relationships. A more nuanced approach is required to better appreciate agential roles in the context of service provision for vulnerable consumers. By using TSM, we follow other scholars who are seeking to move away from "[...] the previous two party (firm-customer) conceptualization of value creation, extending it to the customer's service network" (McColl-Kennedy et al., 2012, p. 2) and who are acknowledging the essential role of context in a value co-creative collective endeavour ( $\mathrm{Ng}$ and Vargo, 2018). The term, TSM, is an all-encompassing term representing the array of value co-creating activities in vulnerable consumption contexts - at times these actors are service providers, consumer advocates, service gatekeepers and risk analysts. In what follows, we describe these roles in a value creation framework.

\section{Theoretical framework}

Prahalad and Ramaswamy (2004) conceptualise the building blocks of value creation as: the dialogue and communication between stakeholders; the ability of stakeholders to access and share data; the ability to monitor risk-benefits; and, finally, the transparency among stakeholders eliminating information barriers, thus creating the acronym DART. However, vulnerable consumers in our research context are often not the "informed, connected, empowered and active consumers" 
Prahalad and Ramaswamy (2004, p. 6) conceptualise as creating value in the service relationship. Importantly, the vulnerable consumer's involvement in the co-creation experience is often very separate from the service provider. Thus, the mutual and reciprocal actions that constitute value co-creation consequently rely on mediation.

We put forward a framework for understanding valuecreating activities in those services that rely on mediation, where vulnerable consumers either lack individual agency to be active value co-creators or are restricted by the systems and processes of the service delivery model. The value configuration space described by Blocker and Barrios (2015) of service design; social structures (Giddens, 1984); service practices; and human agents creating value for themselves, is extended to include mediating actors as agents whose actions can facilitate or stand in place of the vulnerable consumer's capabilities and freedoms. We position these TSM roles according to whether they predominantly reflect a relationship from the service provider to the beneficiary, in other words, the mediator acts as an intermediary or to the service provider from standing alongside the consumer, whereby the mediator acts as an apomediary. The TSMs also interact with each other in the service processes. In addition, there also exists interlocking systems, processes and institutional norms within, which the agential roles of the TSMs operate and which influence the nested layers of service interactions, value co-creation capabilities and individual agency. The mutually influencing social structures and agency (Giddens, 1984); therefore, contextualise the roles of mediating actors in service provision for vulnerable consumers. By identifying these concepts and demonstrating their interrelationships, we use Breidbach and Brodie's (2016) recommendation to develop midrange theories. Figure 1 provides an overview of the theoretical framework.

Intermediaries and apomediaries are differentiated in our theoretical framework. Intermediaries are typically considered as "standing between" the customer and the firm to facilitate the exchange process instigated by the firm. Intermediaries leverage others' resources, for example, they may facilitate access and reduce information barriers, but they neither engage directly in interactive, value-creating processes nor modify resources in this process (Latour, 2005; Storbacka et al., 2016). We propose that in transformative service provision there are also resource integrating actors who "stand by the side" of a vulnerable consumer in the holistic service value (co)-creation processes. To describe these actors we adopt the term apomediary, meaning by the side of or next to (from the Latin Apo). Although more commonly applied in an online information context to describe someone who is an information professional working on behalf of the consumer (Eysenbach, 2008), the term is highly relevant in a service system given the importance of shared information (Maglio et al., 2009). The transformative apomediary stands by the side of the vulnerable consumer in a peer-to-peer or horizontal form of exchange that enhances well-being.

Further, we build on the work of McColl-Kennedy et al.'s (2012) patient co-creation practice styles and the serviceprovider led activities of the DART framework by mapping TSM roles and activities on to the DART framework (Figure 2). We conceptualise the transformative apomediary roles as: voicing service needs, being a service co-designer, enabling benefits and managing risks and acting as the vulnerable consumer's advocate. With parallels to its use in the context of online information seeking (Eysenbach, 2008), the transformative apomediary is considered a trustworthy ally, one who guides consumers to information and services of high quality, facilitates learning and negotiates with the service provider. The transformative apomediary is often the "face and voice" of the vulnerable service consumer.

The intermediary roles, however, purposefully support the service organisation, assisting the vulnerable consumers with service processes and beneficial outcomes, but in a more hierarchical relationship where the vulnerable consumer is dependent on information, protocols or processes arranged or controlled by the intermediary. Intermediaries may at times vet information, passing on what is considered relevant. The intermediary can often reduce information asymmetry characteristic of many transformative services. Thus, intermediaries are typically recognised for their expertise and qualifications for the roles they assume, which we conceptualise as information broker, service integrator, translator of risks and acting as the service provider's advocate.

The TSM role distinctions are not absolute and transformative service interactions will include both. However, we hypothesis that distinguishing between mediating roles in vulnerable consumption contexts can provide a deeper understanding of these service interactions, and ultimately, opportunities to enhance transformative outcomes.

To provide a greater understanding of the TSM role, an illustration is provided. Foster care is used as an example, however, the TSM role applies in other situations, such as aged care, healthcare, disability support services and in other situations.

\section{A case scenario - foster care}

Towards understanding consumer vulnerability and the role of TSMs, we use foster care as an illustration. This understanding is developed through the personal experience of the service context, reinforced by academic literature, to illustrate the TSM roles. While it is out of the scope of this paper to develop the application of TSM in other contexts of vulnerability, such contexts could include persons with a disability impacting on communication in any way or migrants who do not speak the local language and require a mediator to act on their behalf. However, the premise of the current paper is to explore the TSM role within foster care, with the foster child deemed the vulnerable consumer.

Spotswood and Nairn (2016, p. 212) contend that "due to the particular nature of children's agency in relation to societal structures", children are a special case of consumer vulnerability. Their particular characteristics mean that freedom is often restricted and other actors take on mediating roles in service processes. Some research explores how vulnerable consumers co-create (Sharma et al., 2017) and there are calls for increasing research on service design for inclusion, potentially reducing vulnerability and suffering (Fisk et al., 2018). However, there has been limited scholarly attention on mediating roles as a means to encourage service inclusiveness or enhancing well-being outcomes in service systems and service encounters with vulnerable child consumers. Children, 
Figure 1 Theoretical framework of TSMs, agency and structure in the context of service relationships with vulnerable consumers

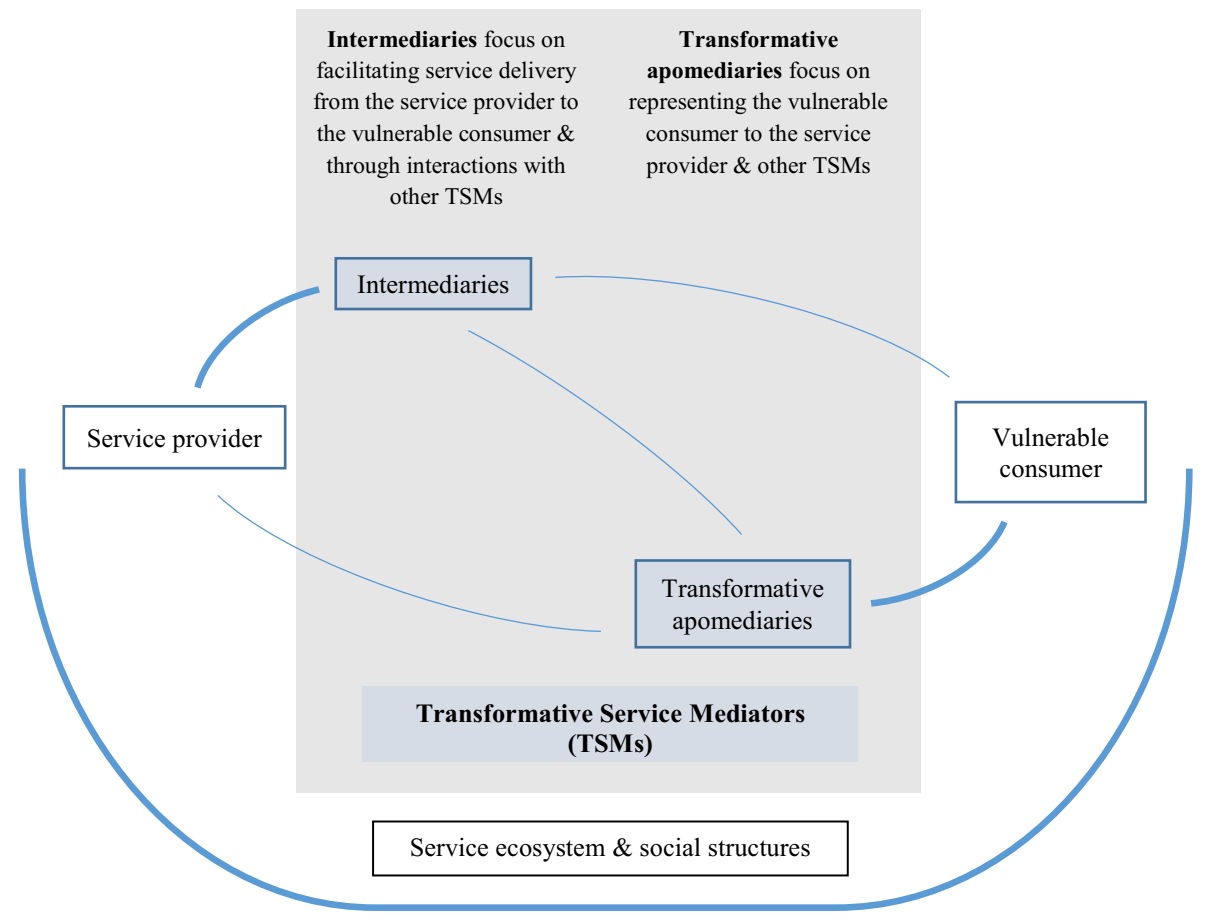

Figure 2 Transformative services for vulnerable consumers - TSMs' value-creating activities and DART

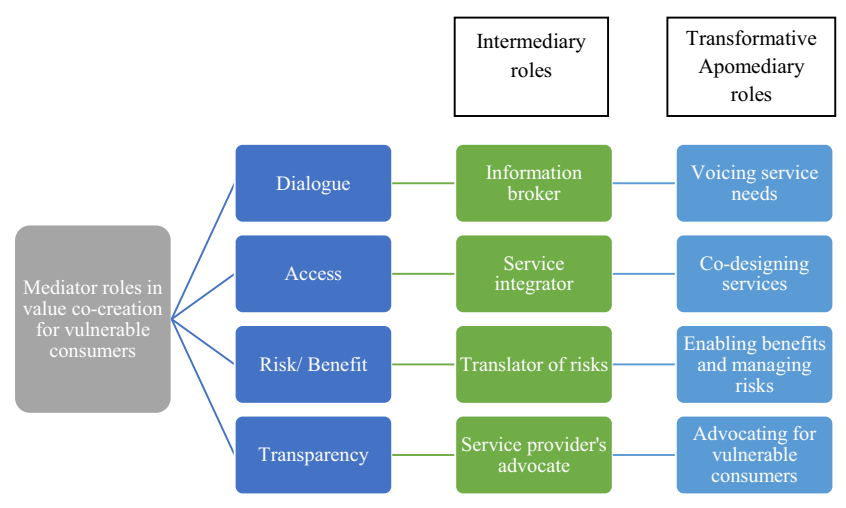

therefore, offer an interesting focus on consumer vulnerability, and this is further heightened in a foster care scenario through the experiences of being in out of home care (also referred to as foster care).

In $2017,47,915$ children were in out-of-home care within Australia (AIHW, 2018), a number that has grown rapidly over recent years (McHugh et al., 2013). Foster care aims to provide a child-centred approach for children, who are unable to remain living with their birth family. Generally, foster children are removed from their biological family or homes and placed in out-of-home care, where the carer is authorised by the service provider. Some foster carers decline financial subsidies and provide care voluntarily. Importantly, foster children often experience disrupted care causing considerable stress for carers and resulting in high carer turnover (Kim and Kao, 2014), as well as adding to the vulnerability of these children
(McGuinness and Arney, 2012). Government-sponsored reports regularly emphasise that out-of-home care requires immediate reform (CSCAC, 2005; QCMC, 2004). This stressed system potentially results in poor emotional, mental and physical health for staff, foster carers and foster children. Thus, many of the service structures are additional triggers for vulnerability. In addition, foster children often have backgrounds of disadvantage and associated health and behavioural issues (AIHW, 2018) that exacerbate their vulnerability.

Pressures on the foster care system may be the result of service failure or they may be related to the number of agents operating within service delivery. Figure 3 demonstrates a model of foster care agents involved in the service to the foster child across multiple levels and with various direct and indirect relationships. This overview demonstrates how mediators operate at the micro and meso levels of service delivery in foster care. It shows that the foster child and foster carer(s) are the recipients of numerous service interactions and relationships, such as child protection services, who may provide a background on the child, decisions on birth family contact arrangements and legal support; a therapeutic assessor, who provides input into the child's needs for increased well-being; support from various medical professionals, who specialise in trauma in children; and the support of a caseworker, who acts as an overall contact and should provide support. A counsellor also operates to provide services to the foster carer, who may experience distress through caring for a child who has experienced trauma. The number and frequency of these interactions put pressure on both child and foster carer impacting stress levels and well-being, despite the intention of providing support and increasing well-being for carer and child. Through varying agendas, requirements and repeated 
Figure 3 The Foster care system in the service ecosystem

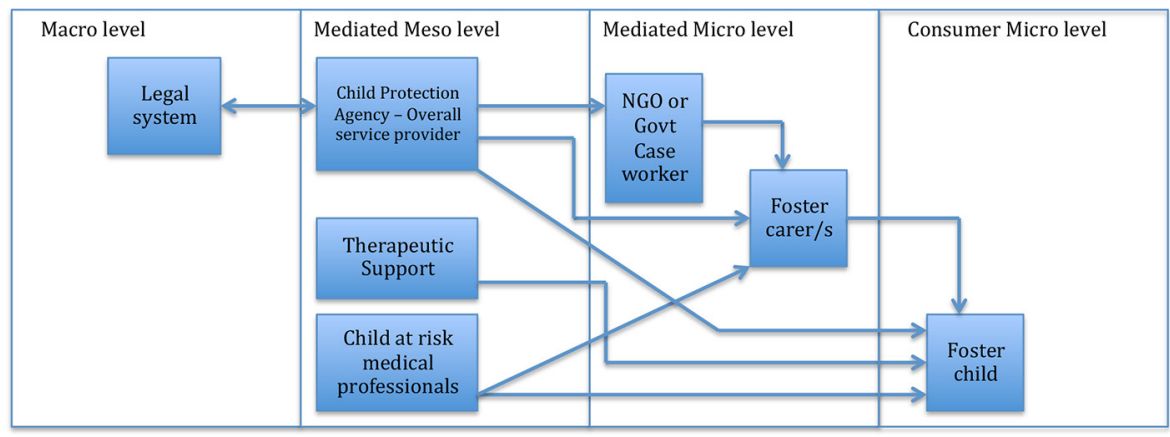

Note: NGO stands for "non-government organisation"

conversations, well-being can be negatively impacted, despite the service provider goal being to enhance the well-being of the child in care and support the foster carer. The foster carer acts as a TSM in service delivery through their relationships within the service ecosystem. Furthermore, to recruit carers, positive stories about foster care experiences are important, and therefore, it is essential that service interactions with foster carers are effective and boost well-being for the carer, and ultimately the child.

We propose that foster children represent a special context for understanding vulnerable consumers and the actors involved in service delivery to these vulnerable consumers. Children in foster care exhibit a double jeopardy regarding vulnerability due to their age (powerlessness) and their lack of agency in the service experience of foster care. Through not choosing to be consumers of service, and due to age, foster children experience a separation from the service provision, though the service provision in itself has considerable implications for their well-being. In particular, foster children typically have few resources and lack voice with respect to institutional processes and systems, due to age, capacity and role in the service process. At the same time, these factors are accompanied by high dependency on other actors who mediate between the service provider, the foster care environment and the foster child.

Although foster children increase their personal contact with the service provider as they age, they are predominantly dependent on mediators for voicing their needs, expressing satisfaction or dissatisfaction and deciding risks. Particularly relevant in this research context is the notion that "the route out of vulnerability [...] lie[s] in the empowered hands of groups of agentic people [...]" (Spotswood and Nairn, 2016, p. 217), who are instrumental in transformative outcomes for the foster child. Foster carers are recruited as service consumers, and, in turn, provide service to the children in their care. However, foster carers rarely view themselves as a service provider; instead, they see their role as providing a stable family environment as a facilitator. Foster carers typically perceive their input as transformative for the foster child, because the child is the ultimate beneficiary of the transformative service. Through these roles foster carers acknowledge they are neither service beneficiaries nor service providers; thus, supporting our argument for service researchers and providers to take a more nuanced approach to understanding their roles as TSMs.
As previously mentioned, the foster care scenario is included to provide a greater understanding of the TSM role, but is not an exhaustive example. For example, the TSM could be someone acting on behalf of someone with a disability or facilitating extra support in an educational setting. Each scenario would differ, and therefore require research. The research agenda discussed in the next section.

\section{Research questions and future research}

Discussion

Ostrom et al. (2015) call on service researchers to develop more understanding in a number of key areas. This paper responds to calls for research in two of those areas - developing understanding of service networks and multi-actor interactions; and improving well-being through transformative service. This paper has sought to understand the purpose and activities of resource-integrating actors who mediate in the value creation process in service relationships with vulnerable consumers. We argue that understanding the TSM roles supports value creation with and service delivery to the end user; in this case the vulnerable consumer.

The illustration of the foster care service system highlights the interactions that can occur when mediators play a role in service delivery on behalf of a vulnerable consumer. We conceptualise these mediators as falling into the following two categories: transformative apomediaries and intermediaries to better understand the nuanced behaviours within the complex foster care service. Each service industry situation would vary based on the needs of the vulnerable consumer in the context, but it was out of the scope of the paper to review each industry. For example, a consumer dealing with education service would have different needs to someone requiring support for tourism services and so on. Similarly, the varying needs of the vulnerable consumer also results in changes in interactions - for example, an adult with a particular type of disability will have different requirements from another adult with another disability, and these needs will differ from someone of a young age (e.g. a foster child). Our scenario, therefore, provides an example towards further understanding of the role of the mediator. Furthermore, the scenario alerts researchers and service providers to the complexity of service relationships, where resource integrating actors mediate in the space between the service provider and the vulnerable consumer. 
We argue that for enhanced well-being, the vulnerable consumer should be empowered as much as possible and that TSM activities can diminish the service consequences of vulnerability. Furthermore, extending the DART model with TSM roles highlights opportunities, where service providers can enhance well-being where vulnerability exists. In particular, it is essential to communicate effectively and openly to build trust and ensure effective service provision and value creation among all parties. Transparency related to decision-making is necessary, and access must be provided as necessary. Due to the number of parties involved in service provision, risk increases and data must be protected to ensure privacy. Service provision to vulnerable consumers is a complicated, multifaceted situation, and the role of the TSM must be valued and supported to ensure value is provided to all parties.

Exploring how mediators enable or constrain transformative service outcomes for vulnerable consumers, we propose that there are gaps in the service literature surrounding consumer vulnerability. In particular, other resource-integrating actors in the service ecosystem who are neither truly consumers nor truly service providers are under-researched. We suggest that cocreation processes require mediating activities in contexts of vulnerability and more so when these contexts involve credence based services with asymmetries of power and information. We propose the role of the TSM in value co-creation for the vulnerable consumer warrants further research and conceptualisation.

\section{Sub-questions for future research}

From the overall research question for this paper, a number of important sub-questions can be developed to pursue this research agenda. The following research questions have been developed based on the literature review framework of vulnerability, the DART model and the service ecosystem with a specific focus on the TSM roles. We introduce a series of unique research questions to guide future studies related to TSMs in service co-creation and consumer vulnerability.

\section{Characteristics and roles of the transformative service mediator}

RQ2. What are the unique and shared attributes of the TSM? How do prescribed institutional service roles influence TSM mediation processes?

$R Q 3$. What factors are most influential in determining transformative mediation activities? Under what circumstances can the same actor adopt both roles?

RQ4. How can technology act as an Intermediary with vulnerable consumers? What are the antecedents and consequences for transformative service outcomes when technology is an Intermediary?

RQ5. What are the antecedents and consequences for transformative service outcomes when an organisation (formal or informal) is an intermediary or transformative apomediary?

RQ6. How does the relationship between the vulnerable consumer and the TSM impact on value co-creation with the service provider (e.g. if the relationship is a personal relationship vs a professional relationship)?

RQ7. What are the consequences of TSMs' engagement with service providers?

RQ8. How, and at which touch points, does the TSM intervene?

RQ9. How does the TSM participate in service recovery (if required)? In what way can the TSM work to create value for the vulnerable consumer in service failure?

RQ10. How are the "unique intersections of the institutional arrangements, with which they [the actors] associate themselves" (Vargo and Lusch, 2016, p. 5) played out in the TSM value co-creation processes?

Support for the transformative service mediator

RQ11. How can TSMs be successfully recruited to ensure TSMs are effective at value co-creation and transformation for the vulnerable consumer? How can service providers differentially support intermediaries and transformative apomediaries to ensure transformation through service engagement?

RQ12. What strategies can service providers adopt for maintaining and encouraging motivation of TSMs? What training is required to inform and equip TSMs for positive value co-creation for the vulnerable consumer?

Transformative service mediator roles and the dialogue, access, risk assessment and transparency model

RQ13. What is the effect of mediated dialogue via TSMs on transformative outcomes for the vulnerable consumer? How do intermediaries and transformative apomediaries differentially influence opportunities for dialogue?

RQ14. How do intermediaries and transformative apomediaries at the micro-meso-macro levels engage in service dialogues?

RQ15. How do intermediaries and transformative apomediaries communicate and understand risks and benefits of service for the vulnerable consumer? How do TSMs minimise vulnerability through risk comprehension on behalf of the vulnerable consumer?

RQ16. How do intermediaries and transformative apomediaries influence opportunities and barriers for transparency required to facilitate value co-creation between actors to benefit the vulnerable consumer? How do mediators gate-keep service aspects?

RQ17. What are the transformative outcomes and DART consequences when service delivery is initiated by 
intermediaries and transformative apomediaries? Does the role of the initiator vary the service outcome? How can service providers design service roles of TSMs to better support the DART elements?

- Individual characteristics:

RQ18. How do intermediaries and transformative apomediaries meet the challenges of responding to idiosyncratic characteristics of vulnerability? How does this vary across the micro-mesomacro levels? To what extent do individual characteristics (of vulnerability) impact TSM involvement?

- Individual states:

RQ19. How do TSMs reduce vulnerability caused by individual states? How does this personalise value co-creation?

$R Q 20$. How does value co-creation and reliance on the TSM differ between those with temporary vulnerability versus those with permanent or long-term vulnerability?

- External conditions:

RQ21. When and how do intermediaries and transformative apomediaries transform the service environment to reduce suffering and reduce disadvantage? How can service providers involve TSMs in service systems and delivery processes to reduce vulnerability? How do TSM roles increase vulnerability? When transformative service channels increase vulnerability (e.g. via social media) how can TSMs mitigate these impacts?

\section{Implications for theory and practice and concluding remarks}

\section{Implications for theory}

Service researchers increasingly consider value co-creation in their research. Our research indicates the importance of considering value creation with vulnerable consumers limited in their ability to co-create. Our theoretical contribution is in the theoretical framework and the mediating resourceintegrating activities inherent in some service relationships. In addition, we make a contribution in a research agenda to guide further exploration of TSM roles. Service researchers exploring vulnerable consumers are encouraged to use these research questions in their research.

We further alert researchers to the relevance of the DART model in value creation between service provider, the TSM and vulnerable consumer. Insightful consideration of the elements of DART has the potential to lead to a lessening of vulnerability and greater participation in transformative service provision. Due to the complex layers of service interactions in the context of vulnerable consumers, this is particularly significant where an actor acts on behalf of the vulnerable consumer.

\section{Implications for managerial practice}

This conceptual paper, and more specifically the concept of TSMs, offers valuable implications for service providers engaged with vulnerable consumers. In particular, by acknowledging and supporting the important roles of the TSMs, service providers will, in turn, be supporting the vulnerable consumer to better realise his/her individual service exchange goals. Consequently, these managerial practices will reduce disadvantage and dependency for the vulnerable consumer contributing to his/her enhanced agency and empowerment.

Service organisations should consider training programmes for TSM roles to ensure their transformative activities are clearly articulated and facilitated. Communication must be transparent and effective, however, the privacy of the vulnerable consumer and security risks must be managed effectively through this open communication. Finally, organisations should minimise service triggers for further vulnerability and diminished perceptions of self among the vulnerable consumers. All of which, we argue, has the potential to build resilience and capacity among vulnerable consumers through facilitating interactions with the TSM.

\section{A challenge for service researchers}

Responding to Ostrom et al.'s (2015) call to further research in value co-creation within service networks and systems and to expand understanding of well-being through service provision, this paper provides a conceptual understanding of the mediator roles in value co-creation on behalf of vulnerable consumers. The most vulnerable of consumers are frequently the most incapacitated and therefore, require an actor to act with them. We classify these roles as TSMs. The TSM provides service to the vulnerable consumer through acting as a recipient of service, and therefore encompasses more activities than solely being an intermediary. While this paper provides an introduction to understanding the TSM role, and through the foster care scenario offers an overview of how this role is implemented, further research is required to operationalise the TSM concept.

We suggest that the role of mediator actor interactions at each level of the service ecosystem is a promising area for service researchers and service providers. In particular, it is important for transformative service researchers to undertake qualitative research to understand the roles and motivations of TSMs in providing value co-creation for vulnerable consumers. The research questions provided can be used to support such research. Quantitative research can also be undertaken to provide more generalisable empirical data to advance insights in the important context of service relationship vulnerability. Undertaking research on various industry contexts will also help to grow understanding of the TSM role. Finally, service providers risk overlooking opportunities for enhanced wellbeing without a more nuanced understanding of TSM roles.

The research agenda provided in this paper will assist researchers to further research in TSR, value co-creation and understanding vulnerable consumers. Service researchers are called on to consider the role of the TSM in service delivery, rather than solely thinking of direct interaction in value cocreation; therefore, furthering understanding in this space. 


\section{References}

Akaka, M. and Chandler, J. (2011), "Roles as resources: a social roles perspective of change in value networks", Marketing Theory, Vol. 11 No. 3, pp. 243-260.

Anderson, L., Ostrom, A.L. and Bitner, M.J. (2011), "Surrounded by services: a new lens for examining the influence of services as social structures on wellbeing", Working paper, W. P. Carey School of Business, Arizona State University.

Anderson, L., Spanjol, J., Jefferies, J.G., Ostrom, A.L., Nations Baker, C., Bone, S.A., Downey, H., Mende, M. and Rapp, J.M. (2016), "Responsibility and well-being: resource integration under responsibilization in expert services", fournal of Public Policy and Marketing, Vol. 35 No. 2, pp. 262-279.

Anderson, A., Ostrom, A., Corbus, C., Fisk, R., Gallan, A., Giraldo, M., Mende, M., Mulder, M., Rayburn, S., Rosenbaum, M., Shirahada, K. and Williams, J. (2013), "Transformative service research: an agenda for the future", Fournal of Business Research, Vol. 66 No. 8, pp. 1203-1210.

Andreasen, A.R. and Manning, J. (1990), "The dissatisfaction and complaining behaviour of vulnerable consumers", Fournal of Consumer Satisfaction, Dissatisfaction and Complaining Behaviour, Vol. 3, pp. 12-20.

Archer, M. (2000), Being Human: The Problem of Agency, Cambridge University Press, Cambridge, MA.

AIHW (Australian Institute of Health and Welfare) (2018), "Child protection Australia 2016-17", Child Welfare Series no. 68, Cat. No. CWS 63, AIHW, Canberra.

Baker, S.M. and Mason, M. (2012), "Toward a process theory of consumer vulnerability and resilience: illuminating its transformative potential", in Mick, D.G., Pettigrew, S., Pechmann, C. and Ozanne, J.L. (Eds), Transformative Consumer Research for Personal and Collective Well-Being, Taylor \& Francis, New York, NY, pp. 543-563.

Baker, S., Gentry, J. and Rittenburg, T. (2005), "Building understanding of the domain of customer vulnerability", Fournal of Macromarketing, Vol. 25 No. 2, pp. 128-139.

Blocker, C.P. and Barrios, A. (2015), "The transformative value of a service experience", Fournal of Service Research, Vol. 18 No. 3, pp. 265-283.

Breidbach, C.F. and Brodie, R.J. (2017), "Engagement platforms in the sharing economy: conceptual foundations and research directions", fournal of Service Theory and Practice, Vol. 27 No. 4, pp. 761-777.

Commonwealth Senate Community Affairs Committee (CSCAC) (2005), Protecting Vulnerable Children: A National Challenge, CSCAC, Canberra.

Commuri, S. and Ekici, A. (2008), "An enlargement of the notion of consumer vulnerability", fournal of Macromarketing, Vol. 28 No. 2, pp. 183-186.

Crockett, D., Downey, H., Firat, A.F., Ozanne, J.L. and Pettigrew, S. (2013), "Conceptualizing a transformative research agenda”, fournal of Business Research, Vol. 66 No. 8, pp. 1171-1178.

Dickson, T.J., Darcy, S., Johns, R. and Pentifallo, C. (2016), "Inclusive by design: transformative service and sport-event accessibility", The Service Industries fournal, Vol. 36 Nos 11/12, pp. 532-555.

Dodds, S. (2014), "Dependence, care, and vulnerability", in Mackenzie, C., Rogers, W. and Dodds, S. (Eds), Vulnerability:
New Essays in Ethics and Feminist Philosophy, Oxford University Press, New York, NY, pp. 181-203.

Edvardsson, B., Kleinaltenkamp, M., Tronvoll, B., McHugh, P. and Windahl, C. (2014), "Institutional logics matter when coordinating resource integration", Marketing Theory, Vol. 14 No. 3, pp. 291-309.

Eysenbach, G. (2008), "Medicine 2.0: social networking, collaboration, participation, apomediation, and openness", Fournal of Medical Internet Research, Vol. 10 No. 3, p. e22.

Fisk, R.P., Dean, A.M., Alkire, L., Joubert, A., Previte, J., Robertson, N. and Rosenbaum, M.S. (2018), "Design for service inclusion: creating inclusive service systems by 2050", Fournal of Service Management, Vol. 29 No. 5, pp. 1-25.

FitzPatrick, M., Varey, R.J., Grönroos, C. and Davey, J. (2015), "Relationality in the service logic of value creation", Fournal of Services Marketing, Vol. 29 Nos 6/7, pp. 463-471.

Giddens, A. (1984), The Constitution of Society: Outline of the Structuration Theory, University of CA Press, Berkley, CA.

Giesler, M. and Veresiu, E. (2014), "Creating the responsible consumer: moralistic governance regimes and consumer subjectivity", fournal of Consumer Research, Vol. 41 No. 3, pp. 840-857.

Grönroos, C. (2008), "Service logic revisited: who creates value? And who co-creates?", European Business Review, Vol. 20 No. 4, pp. 298-314.

Halstead, D., Jones, M. and Cox, A. (2007), "Satisfaction theory and the disadvantaged consumer", Fournal of Customer Satisfaction, Dissatisfaction and Complaining Behaviour, Vol. 20, pp. 15-35.

Hardyman, W., Daunt, K.L. and Kitchener, M. (2015), "Value co-creation through patient engagement in health care: a micro-level approach and research agenda", Public Management Review, Vol. 17 No. 1, pp. 90-107.

Hepi, M., Foote, J., Finsterwalder, J., Carswell, S. and Baker, V. (2017), "An integrative transformative service framework to improve engagement in a social service ecosystem: the case of He Waka Tapu", Fournal of Services Marketing, Vol. 31 Nos 4/5, pp. 423-437.

Hogg, M.K., Howells, G. and Milman, D. (2007), “Consumers in the knowledge-based economy (KBE): what creates and/or constitutes consumer vulnerability in the KBE?", Fournal of Consumer Policy, Vol. 30 No. 2, pp. 151-158.

Hudson, P.L., Trauer, T., Graham, S., Grande, G., Ewing, G., Payne, S., Stajduhar, K.I. and Thomas, K. (2010), “A systematic review of instruments related to family caregivers of palliative care patients", Palliative Medicine, Vol. 24 No. 7, pp. 656-668.

Johns, R.,. Darcy, S. and Dickson, T. (2017), "Transformative service and co-creation for more accessibility", paper presented at the 26th Frontiers in Services Conference, 22-25 June, Fordham University, New York, NY.

Kim, H. and Kao, D. (2014), "A meta-analysis of turnover intention predictors among US child welfare workers", Children and Youth Services Review, Vol. 47, pp. 214-223.

Klaus, P. and Maklan, S. (2007), "The role of brands in a service dominated world", Fournal of Brand Management, Vol. 15 No. 2, pp. 115-122.

Kleinaltenkamp, M., Brodie, R.J., Frow, P., Hughes, T., Peters, L.D. and Woratschek, H. (2012), "Resource integration", Marketing Theory, Vol. 12 No. 2, pp. 201-205. 
Latour, B. (2005), Reassembling the Social: An Introduction to Actor-Network-Theory, Oxford University Press, Oxford.

Leino, H. (2017), "Secondary but significant: secondary customers' existence, vulnerability, and needs in care services", Fournal of Services Marketing, Vol. 31 No. 7, pp. 760-770.

Lusch, R.F. and Vargo, S.L. (2014), The Service-Dominant Logic of Marketing: Dialog, Debate, and Directions, Routledge, New York, NY.

McAlexander, J.H., Schouten, J.W. and Roberts, S.D. (1993), "Consumer behavior and divorce", Research in Consumer Behavior, Vol. 6, pp. 153-184.

McColl-Kennedy, J.R., Vargo, S.L., Dagger, T.S., Sweeney, J. C. and van Kasteren, Y. (2012), "Health care customer value cocreation practice styles", fournal of Service Research, Vol. 15 No. 4, pp. 370-389.

McGuinness, K. and Arney, F. (2012), Foster and Kinship Care Recruitment Campaign Literature Review, Centre for Child Development and Education, Child Protection Research Program, Menzies School of Health Research on behalf of the Caring for Kids Consortium, Darwin, NT.

McHugh, M., Pell, A. and Street, B. (2013), Reforming the Foster Care System in Australia, UNSW Social Policy Research Centre, Sydney, pp. 37-38.

McKeage, K., Crosby, E. and Rittenburg, T. (2018), "Living in a gender-binary world: implications for a revised model of consumer vulnerability", fournal of Macromarketing, Vol. 38 No. 1, pp. 73-90.

Maglio, P.P., Vargo, S.L., Caswell, N. and Spohrer, J. (2009), "The service system is the basic abstraction of service science", Information Systems and e-Business Management, Vol. 7 No. 4, pp. 395-406.

Mansfield, P.M. and Pinto, M.B. (2008), "Consumer vulnerability and credit card knowledge among developmentally disabled citizens", Fournal of Consumer Affairs, Vol. 42 No. 3, pp. 425-438.

Nasr, L. and Fisk, R.P. (2018), "The global refugee crisis: how can transformative service researchers help?", The Service Industries fournal, pp. 1-17.

Ng, I.C. and Vargo, S.L. (2018), "Service-dominant (SD) logic, service ecosystems and institutions: bridging theory and practice", fournal of Service Management, Vol. 29 No. 4, pp. 518-520.

Ostrom, A., Parasuraman, A., Bowen, D., Patricio, L. and Voss, C. (2015), "Service research priorities in a rapidly changing context", fournal of Service Research, Vol. 18 No. 2, pp. 127-159.

Payne, A., Storbacka, K. and Frow, P. (2008), "Managing the co-creation of value", fournal of the Academy of Marketing Science, Vol. 36 No. 1, pp. 83-96.

Pera, R. and Viglia, G. (2015), "Turning ideas into products: subjective well-being in co-creation", The Service Industries fournal, Vol. 35 Nos 7/8, pp. 388-402.

Prahalad, C. and Ramaswamy, V. (2004), "Co-creating unique value with customers", Strategy and Leadership, Vol. 32 No. 3, pp. 4-9.
QCMC (Queensland Crime and Misconduct Committee) (2004), Protecting Children: An Inquiry into Abuse of Children in Foster Care, Queensland Crime and Misconduct Committee, Brisbane,

Ringold, D.J. (2005), "Vulnerability in the marketplace: concepts, caveats, and possible solutions", fournal of Macromarketing, Vol. 25 No. 2, pp. 202-214.

Rosenbaum, M., Seger-Guttmann, T. and Giraldo, M. (2017), "Commentary: vulnerable consumers in service settings", Fournal of Services Marketing, Vol. 31 Nos 4/5, pp. 309-312.

Rosenbaum, M., Corus, C., Ostrom, A., Anderson, L., Fisk, R., Gallan, A., Giraldo, M., Mende, M., Mulder, M., Rayburn, S., Shirahada, K. and Williams, J. (2011), "Conceptualization and aspirations of transformative service research", Fournal of Research for Consumers, Vol. 19, pp. 1-6.

Saatcioglu, B. and Corus, C. (2016), "Exploring spatial vulnerability: inequality and agency formulations in social space", fournal of Marketing Management, Vol. 32 Nos 3/4, pp. 230-251, doi: 10.1080/0267257X.2015.1103775.

Sharma, S., Conduit, J. and Hill, S.R. (2017), "Hedonic and eudaimonic well-being outcomes from co-creation roles: a study of vulnerable customers", Fournal of Services Marketing, Vol. 31 Nos 4/5, pp. 397-411.

Sewell, W.H. Jr (1992), “A theory of structure: duality, agency, and transformation", American fournal of Sociology, Vol. 98 No. 1, pp. 1-29.

Spotswood, F. and Nairn, A. (2016), "Children as vulnerable consumers: a first conceptualisation", Fournal of Marketing Management, Vol. 32 Nos 3/4, pp. 211-229.

Storbacka, K., Brodie, R.J., Böhmann, T., Maglio, P.P. and Nenonen, S. (2016), "Actor engagement as a microfoundation for value co-creation", Fournal of Business Research, Vol. 69 No. 8, pp. 3008-3017.

Street, B.V. (2001), Literacy and Development: Ethnographic Perspectives, Routledge, London.

Sweeney, J., Danaher, T. and McColl-Kennedy, J. (2015), "Customer effort in value cocreation activities improving quality of life and behavioral intentions of health care customers", Fournal of Service Research, Vol. 18 No. 3, pp. 318-335.

Vargo, S.L. and Lusch, R.F (2004), "Evolving to a new dominant logic for marketing", fournal of Marketing, Vol. 68 No. 1, pp. 1-17.

Vargo, S.L. and Lusch, R.F (2006), "Service-dominant logic: what it is, what it is not, what it might be", in Lusch, R.F and Vargo, S.L. (Eds), The Service-Dominant Logic of Marketing: Dialog, Debate, and Directions, ME Sharpe, Armonk, NY, pp. 43-56.

Vargo, S. and Lusch, R. (2016), "Institutions and axioms: an extension and update of service-dominant logic", fournal of the Academy of Marketing Science, Vol. 44 No. 1, pp. 5-23.

Westcott, R. (Ed.) (2005), The Certified Manager of Quality/ Organizational Excellence Handbook, 3rd ed., ASQ Quality Press, Milwaukee, WI.

\section{Corresponding author}

Raechel Johns can be contacted at: Raechel.Johns@ canberra.edu.au 